\title{
El uso de Whatsapp en un museo
}

\section{Using whatsapp in a museum}

\section{Elena Moreno Pascual}

Fundación de Arte Ibáñez Cosentino, Museo de Arte de Almería. comunicacionmuseodearte@.gmail.com. @ElenaMPasc

\section{Resumen}

El ritmo y la manera de comunicarnos están cambiando en los últimos años a pasos agigantados. Cada vez son más las personas que se comunican a través de medios digitales como mail, redes sociales o Whatsapp. De esta última aplicación es de la que nos ocuparemos, ya que su uso va en constante aumento.

Todos conocemos Whatsapp, pero Whatsapp Business (también gratuita) implementa algunas funciones como las estadísticas y la automatización, lo cual facilita la comunicación con el visitante/usuario de cualquier institución cultural, como los museos, de una manera directa, instantánea y personalizada. Incluso para aquellas instituciones con recursos limitados.

Algunos ejemplos del uso de Whatsapp Business que durante seis años nos están dando muy buenos resultados en el Museo de Arte de Almería son la promoción de nuestras exposiciones y actividades, así como la reserva de plazas para asistir y participar en ellas, o la consulta de la información general del museo, entre otras acciones.

Tras este tiempo utilizando Whatsapp Business en las dos sedes del museo de arte de Almería podemos afirmar que es una herramienta de comunicación y de marketing cultural muy valiosa para acercar la institución a nuestros usuarios/visitantes haciéndolos sentir únicos y especiales.

Palabras clave: Comunicación; Marketing Cultural; Museos; Whatsapp; Cultura.

\footnotetext{
Abstract

The pace and manner of communication is changing in recent years in leaps and bounds. More and more people are communicating through digital media such as mail, social networks or Whatsapp. This latter application is the one we will deal with, as its use is increasing.

We all know Whatsapp, but Whatsapp Business (also free) implements some functions like statistics and automation, which facilitates communication with
} 
the visitor/user of any cultural institution, such as museums, in a direct, instantaneous and personalized way. Even for those institutions with limited resources.

Some examples of the use of Whatsapp Business that for six years are giving us very good results in the Museum of Art of Almeria are the promotion of our exhibitions and activities, as well as the reservation of places to attend and participate in them, or the consultation of the general information of the museum, among other actions.

After this time using whatsapp business in the two venues of the Art Museum of Almeria we can affirm that it is a very valuable communication and cultural marketing tool to bring the institution closer to our users/visitors making them feel unique and special.

Keywords: Communication; Cultural Marketing; Museums; Whatsapp; Culture. 


\section{Introducción}

Entre las distintas acepciones que la Real Academia Española (RAE) propone para el verbo comunicar encontramos las de "descubrir, manifestar o hacer saber a alguien algo", y "conversar, tratar con alguien de palabra o por escrito". Hechos todos ellos connaturales al ser humano, éste buscó desde sus inicios, como ser social por naturaleza que es, medios y formas de comunicarse con otros para conocer o saber de algo.

A lo largo del tiempo, la manera de comunicarse ha ido cambiando, aunque siempre siguiendo el esquema emisor - código - mensaje - medio o canal - receptor. Como todos hemos podido comprobar, desde las últimas décadas del siglo $\mathrm{XX}$, han incidido especialmente en la forma en que nos comunicamos la aparición de nuevos medios y canales digitales, como las plataformas de correo electrónico (medio por el que actualmente se comunican, a diario, más de 3.900 millones de personas a nivel mundial, una cifra que se espera que en 2023 alcance los 4.300 millones); el desarrollo de la red web o $w w w$ en 1989; el surgimiento a partir de 1997, con la creación de OAL Instant Messenger, de las primeras aplicaciones de mensajería instantánea; o la aparición de las primeras redes sociales surgidas en los albores del siglo XXI, con la creación en 2002 de Friendster.

Un boom de herramientas que nuestra sociedad actual incorpora a su día a día en evolución constante, influyendo tanto en nuestra vida personal o laboral, como en sectores tan importantes como la educación o la cultura. Áreas en las que es fácil observar cómo el avance tecnológico y el desarrollo de nuevos medios digitales puede influir en nuestra forma de comunicarnos, tanto desde la institución, como con ésta.

\section{Objetivos}

En este texto nos centraremos en cómo Internet y la tecnología han cambiado también la forma de crear, consumir y, sobre todo, difundir la Cultura desde las instituciones museísticas, a través de nuestra experiencia en la Fundación de Arte Ibáñez Cosentino. Para ello nos centraremos en las acciones digitales de comunicación que desarrollamos en las dos sedes que forman el Museo de Arte de Almería (el Museo de Arte doña Pakyta y el Museo de Arte de Almería - Espacio2), y en concreto en el uso de aplicaciones de mensajería instantánea (Whatsapp Business) como herramientas de comunicación con nuestros usuarios $\mathrm{y}$ visitantes (reales y/o potenciales).

\section{El uso de Whatsapp Business en museos}

Tanto el auge de medios sociales y aplicaciones para comunicarnos, como el crecimiento, y uso, de dispositivos digitales, han creado en el ser humano nuevos hábitos de consumo cultural. Esto ha sido especialmente visible con la irrupción mundial, a principios de 2020, de la pandemia provocada por la COVID-19 y las consecuencias que ésta ha tenido para los museos y resto de instituciones culturales. Como se indica en el informe La Cultura en 
España 2020, editado por la Fundación Contemporánea en enero de 2021, “un 74,7\% (de los encuestados) afirma haber adaptado temporalmente durante la pandemia algunas actividades físicas a un formato digital, mientras un $63,9 \%$ ha creado con carácter extraordinario nuevos contenidos y actividades en soporte digital", y "un 97,4\% reconoce haber experimentado este año un incremento significativo en las audiencias digitales en sus webs y redes sociales". Datos sin duda clarificadores de cómo actualmente la forma de comunicarnos (en cultura) ha cambiado, concediéndose un lugar muy especial a lo digital.

A esto deberíamos añadir, continuando con datos objetivos, que en España, según estadísticas de enero de 2021 aportadas por las empresas Hootsuite y wearesocial.com: el número de internautas ascendía a 42,54 millones, el número de conexiones móviles activas suponían un total de 54,34 millones de usuarios y el número de usuarios de redes sociales ascendía a 37, 40 millones.

Con estos datos, instituciones culturales como los museos, deben seguir apostando por las últimas revoluciones tecnológicas para formar parte del día a día de cada uno de sus usuarios a través de la "pequeña" pantalla del móvil, la tableta o el ordenador, comunicándose de una manera directa con sus usuarios y visitantes, así como con todas aquellas otras personas interesadas, a través del uso de correo electrónico, redes sociales, web o aplicaciones. Una comunidad concreta que, a su vez, formará parte de un gran mundo digital a través del cual todos permanecemos interconectados.

\section{1. ¿Por qué usar una aplicación de mensajería instantánea y cuál?}

Según el informe anual realizado por Hootsuite y wearesocial.com sobre el uso de medios sociales a nivel mundial al que antes nos referíamos, el $88,4 \%$ de personas con edades comprendidas entre los 18 y 64 años usan aplicaciones de redes sociales en sus móviles, y el 90,7\% usa aplicaciones de chat o mensajería instantánea de forma habitual (fig. 1).

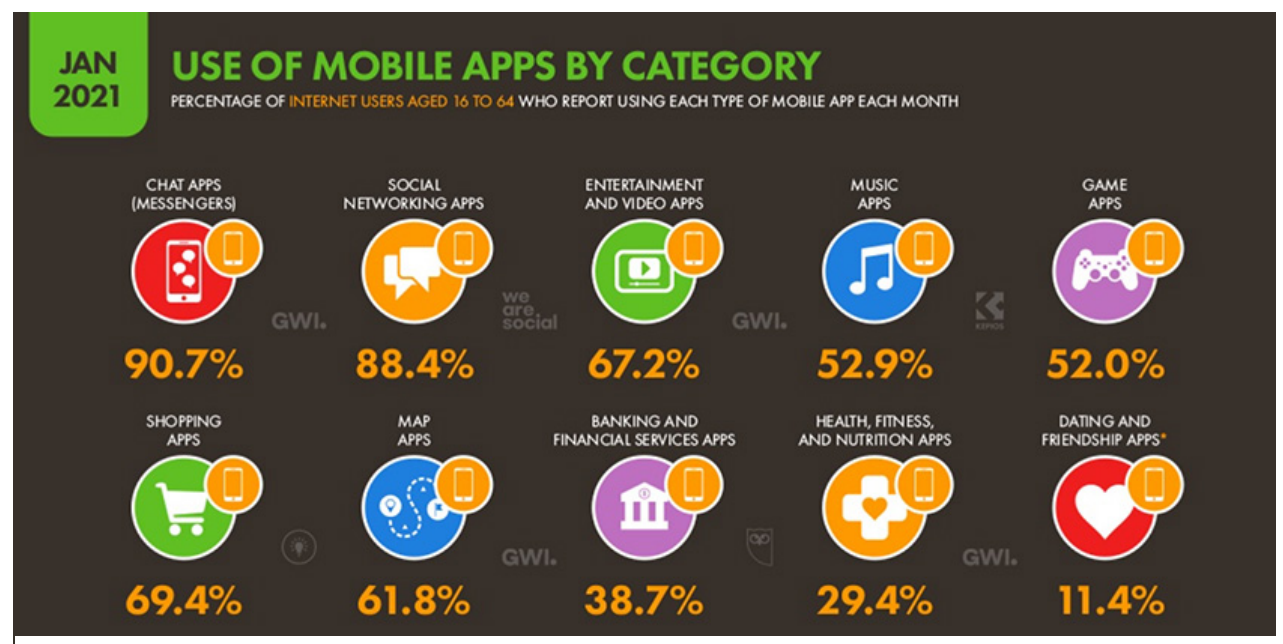

Fig. 1. Informe anual realizado por Hootsuite y wearesocial.com 
Una elevada cifra que, por su incidencia en la sociedad, "invita" a las instituciones culturales, y en particular a los museos, a usar alguna de estas aplicaciones de mensajería.

En España, Whatsapp es la red social con más usuarios: un $85 \%$ de personas con edades comprendidas entre 41 y 54 años la usa, según el Estudio Anual sobre Redes Sociales que realiza la Interactive Advertising Bureau (IAB) en colaboración con Elogia (fig. 2), siendo una de las redes mejor valoradas entre los usuarios, frente al uso de otras aplicaciones como Instagram, TikTok, Facebook, Telegram o Twitter (fig. 3).

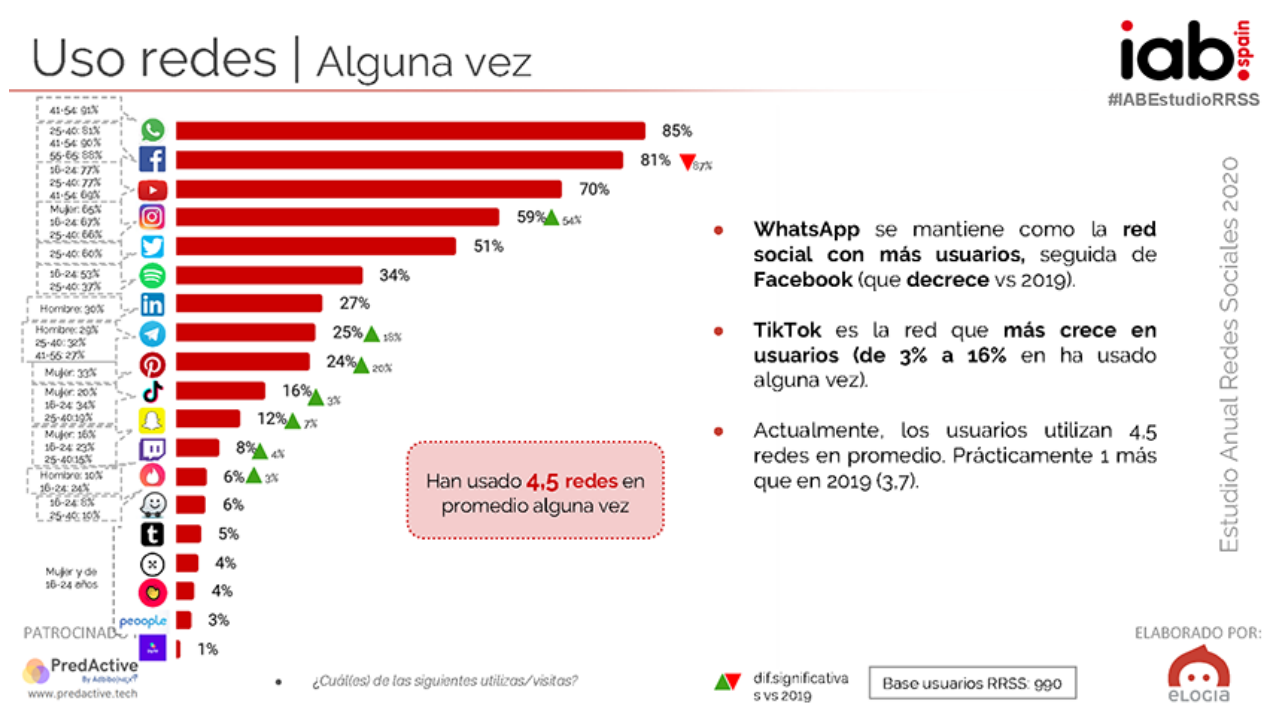

Fig. 2. Uso de redes en España

\section{Valoración de redes | Satisfacción}

- WhatsApp y Youtube se posicionan como las Redes mejor valoradas entre sus usuarios, seguidas de Spotify.

- Mejora la valoración de Youtube, Telegram. Snapchat y Linkedin.

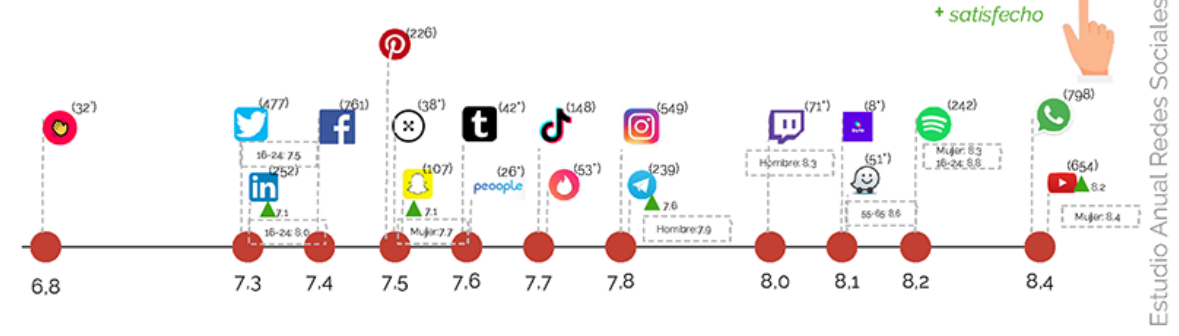

Fig. 3. Valoración de las principales redes sociales en España

\subsection{Whatsapp. Unas notas sobre su historia}


Diseñado en 2009 por Jan Koum, Whatsapp fue el primer servicio de mensajería instantánea creado a nivel mundial. En 2014 fue adquirido por Facebook, desarrollándose a partir de ese momento nuevos servicios, como la incorporación de llamadas gratuitas, videollamadas... La incorporación de estos nuevos servicios y el éxito de la propia aplicación, han llevado a Whatsapp a ser una de las aplicaciones más usadas a nivel mundial, con más de dos billones de usuarios activos mensualmente (fig. 4).

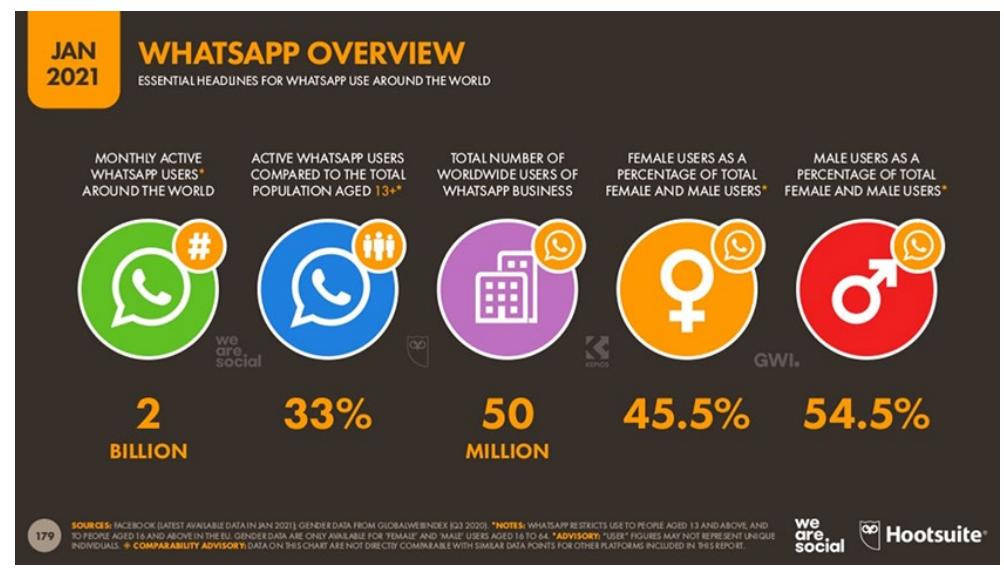

Fig. 4. Uso de Whatsapp a nivel mundial

Tanto es así, que durante años las empresas han tratado de adaptar su funcionamiento a los servicios que ofrecía Whatsapp (con la dificultad añadida que suponía la Ley de Protección de Datos), hasta que en 2018 se lanzase Whatsapp Business. Aplicación que cumple el Reglamento General de Protección de Datos (RGPD) de la Unión Europea, que entró en vigor el 25 de mayo de 2016 y es de aplicación desde el 25 de mayo de 2018.

\subsection{Ventajas del uso de Whatsapp Business}

Al margen de facilitar la comunicación directa entre el emisor y el receptor (como cualquier otra aplicación de mensajería instantánea) el uso en comunicación cultural de Whatsapp Business tiene entre otras ventajas:

- El hecho de ser una aplicación gratuita, lo que permite que cualquier institución pueda descargarla y usarla sin importar su presupuesto.

- La creación de un perfil de empresa: una vez descargada la aplicación, se puede crear un perfil en el que se incluya información (dirección, mail, web...) de la propia empresa o institución. Una información útil que generará confianza en el usuario/receptor a través de la propia marca.

- El uso de etiquetas, permitiendo organizar los contactos a través de aquéllas. 
- La creación de respuestas rápidas y mensajes automatizados, tales como un mensaje de bienvenida, de agradecimiento...

- La creación de listas de difusión, en las que se pueden incluir un máximo de 256 contactos cuyos datos no serán accesibles para el resto (manteniendo la privacidad de los usuarios y del contenido de las comunicaciones que cada uno de éstos pueda mantener con la empresa/institución administradora de la lista), y a través de las cuales se puede enviar un mismo mensaje a todos los integrantes de la lista, siempre que el receptor tenga el número del administrador de la lista guardado en su agenda de contactos.

- La generación de estadísticas: Whatsapp Bussines ofrece la posibilidad de consultar algunas métricas como la cantidad de mensajes enviados, recibidos y leídos (aspecto especialmente útil en marketing).

Todas estas ventajas redundan directamente en los usos que desde instituciones culturales como los museos se pueden hacer de esta aplicación de mensajería instantánea, si bien, como podremos comprobar más adelante, no son las únicas.

\section{El uso de Whatsapp en el Museo de Arte de Almería (Museo de Arte doña Pakyta y Museo de Arte de Almería - Espacio 2). Experiencias y resultados}

Tras casi seis años de experiencia usando esta aplicación (primero Whatsapp y a partir de 2018, Whatsapp Business), podemos afirmar que Whatsapp Business se ha convertido en una de las herramientas imprescindibles de nuestro plan de comunicación y marketing debido, fundamentalmente, a dos aspectos:

- Es una aplicación usada por grupos de diferentes edades, desde jóvenes (20-30 años) hasta tercera edad (mayores de 70 años), franja de edad de gran amplitud en la que quedaría siempre incluido nuestro público objetivo.

- Tras la emisión de cualquier información desde el museo que requiera respuesta por parte de nuestros visitantes o usuarios, hemos podido comprobar que la diferencia de respuesta obtenida siempre es mucho mayor a través de Whatsapp, que respecto a otros medios de comunicación digital, como redes sociales o correo electrónico.

Esto nos ha llevado a implementar el uso de esta aplicación en distintas áreas del museo, como complemento a las líneas de comunicación online y offline de las mismas.

\subsection{Usos de Whatsapp Business en el Museo de Arte de Almería}

Los distintos usos de Whatsapp Business dependen de las diferentes áreas del museo en las que lo usamos. En líneas generales, los tipos de uso de Whatsapp Business en el Museo de Arte de Almería son:

- Promoción y/o difusión de actividades culturales. 
A través de un mensaje de Whatsapp, nuestros visitantes, usuarios o público potencial, se mantiene informado de las exposiciones temporales que tienen lugar en el museo así como de las distintas actividades que se programan mensualmente, como conferencias, conciertos, visitas temáticas, rutas patrimoniales... Algunas de estas actividades requieren reserva previa, que se puede realizar directamente, facilitando los procesos al usuario, a través de Whatsapp.

A esto habría que sumar la posibilidad que la aplicación ofrece al usuario de trasladar al museo sus dudas y que éstas puedan ser solventadas en ese mismo instante, respondiendo directamente desde el museo al mensaje recibido, y aportándole más información y detalles de la actividad a la que desea asistir, creándose una comunicación bidireccional, directa y personal.

- Difusión de actividades vinculadas al Área de educación y divulgación de contenidos digitales didácticos.

Whatsapp Business nos facilita la difusión de actividades didácticas realizadas desde el museo, tanto para adultos, como para familias. En este caso concreto, desde el Museo de Arte de Almería tenemos dos tipos de actuación dependiendo de si la actividad didáctica es presencial, es decir, se va a realizar dentro del espacio museístico, o es creada solo para el ámbito digital.

En el caso de las actividades presenciales siempre la comunicación con nuestros usuarios se inicia con el envío de un mensaje con información básica de la actividad (hora, día, lugar, a qué tipo de público va dirigida...) así como si se requiere reserva previa y cómo realizarla, bien a través de una llamada de teléfono, bien mediante un mensaje de Whatsapp (aunque siempre a través de un único número de teléfono móvil para agilizar la reserva y evitar posibles errores en la gestión de éstas).

Como ejemplo ilustrativo de este uso de Whatsapp Business utilizaremos la difusión de los talleres didáctico-creativos para familias que se realizan en el Espacio 2 del Museo de Arte de Almería: primero enviamos la información del taller a través de un mensaje mediante listas de difusión, llegando de forma inmediata y brindando a todos la oportunidad de acceder a la información y a la reserva de plazas al mismo tiempo, a un gran número de padres y madres interesados. Una vez recibida la información, los padres hacen uso de la mensajería para proceder a reservar sus plazas o trasladarnos cualquier duda o sugerencia dentro de un amplio horario de atención al público de mañana y tarde. Recibida la solicitud por parte del interesado, se comprueba la existencia de plazas e inmediatamente se confirma la reserva (o se indica la no disponibilidad de plazas ya en ese momento), ofreciendo así un servicio de reservas ágil y con muy pocos trámites para el usuario.

En el caso de la divulgación de contenidos digitales didácticos, nuestra comunicación con los usuarios se inicia también con el envío de un mensaje en el que se les propone o invita a participar en la actividad digital creada (visitas guiadas o interactivas, juegos, imágenes interactivas de obras y/o sus autores pertenecientes a la colección del museo...). 
En esta ocasión utilizaremos como ejemplo de este uso de Whatsapp Business los juegos didácticos creados exclusivamente para el ámbito digital, facilitando el conocimiento del museo tanto a adultos, como a niños a través de la gamificación. Para ello se envía un mensaje, a través de la lista de difusión, al usuario detallando la actividad que se le adjunta a través de un enlace directo a la plataforma digital donde se ha creado y se encuentra incluida, en este caso un juego, que desde el museo invitamos a que realicen, participen o compartan. Una vez que el usuario recibe el mensaje, puede acceder al juego inmediata y directamente sin necesidad de abrir ni buscar en otra aplicación, red social o web (algo que nuestros usuarios valoran especialmente). La comunicación vuelve a ser directa y personal, y recibiendo, en muchas ocasiones el emisor del mensaje (el museo) un feedback inmediato respecto a la actividad propuesta y su valoración.

- Contacto con medios de prensa.

A través de la aplicación Whatsapp Business mantenemos una comunicación directa con los medios de prensa de una manera rápida para trasladar información puntual sobre algún acto o actividad. Esta comunicación también se da en línea inversa, ya que los medios de comunicación pueden contactar con el museo por medio de un mensaje de Whatsapp para ampliar información o solventar alguna duda.

\subsection{Valoración de nuestros usuarios respecto al uso de Whatsapp como medio de comunicación}

Tras la consulta a los usuarios de las listas de difusión por Whatsapp del Museo de Arte de Almería respecto a qué medio de comunicación digital con el museo prefieren de todos los que actualmente tenemos activos para la difusión de actividades y divulgación de contenidos (correo electrónico, redes sociales -Facebook y Twitter- y mensajería instantánea -Messenger y Whatsapp-), del total de respuestas recibidas, un 92,8\% confirman que prefieren Whatsapp como medio de comunicación con el museo, frente al 7,2\% que eligen otros medios.

Entre las razones que nuestros usuarios señalan para elegir Whatsapp destacan:

- El ser un medio de comunicación directa y ágil, de acceso inmediato a través del teléfono móvil.

- La comodidad en el acceso a la información, que llega a través de una única vía de comunicación, así como la seguridad que transmite el que la información les llega directamente desde el emisor de la misma (confianza en la marca emisora y ausencia de fakesnews).

- La agilidad en la reserva de plazas para actividades, aspecto especialmente valorado por nuestros usuarios teniendo en cuenta la reducción de aforos devenida de la actual situación sanitaria.

- El fácil uso de la propia aplicación. 
- La transmisión puntual de información y novedades, especialmente valorado por aquellos usuarios que no tienen otras redes sociales o no las usan a diario.

- La inmediatez de respuesta a sus consultas y la atención personalizada al usuario (comunicación bidireccional).

- La facilidad para compartir contenidos enviados desde el museo con otros contactos de su agenda (no incluidos en nuestras listas de difusión).

\section{Conclusiones}

Teniendo en cuenta:

- Las estadísticas de la institución (tanto en el medio físico -participación de usuarios en actividades, visitantes a exposiciones temporales...-, como digital, a través del análisis de datos obtenidos por participación en actividades exclusivas y disfrute de contenidos digitales) y la incidencia que en éstas tiene el uso de medios de comunicación digitales; y

- Las valoraciones y comentarios de nuestros usuarios, reflejados aquí en la encuesta a la que acabamos de hacer referencia,

podemos concluir que, en el caso particular del Museo de Arte de Almería, el uso de Whatsapp y Whatsapp Business es uno de los canales de comunicación digital de mayor aceptación por parte de nuestros usuarios y visitantes.

Por nuestra experiencia, creemos que este modelo de comunicación digital es exportable a otras instituciones culturales o museos (como de hecho ya hacen algunas instituciones andaluzas, como el Museo de Jaén o el Museo de la Autonomía de Andalucía -en La Puebla del Río, Sevilla-, al menos para la reserva de plazas, tal y como se indica en sus páginas web), independientemente de su presupuesto, ya que:

- La descarga y el uso de la aplicación es gratuita.

- Ofrece posibilidades como la creación de listas de difusión, permitiéndonos economizar tiempo de trabajo.

- Su uso es fácil e intuitivo.

- Permite el envío de distintos tipos de archivo que pueden complementar la información vertida en el cuerpo del mensaje (pdf, imágenes, enlaces...).

Cuatro razones que se suman a los datos que las propias estadísticas nos ofrecen, como ya se ha señalado con anterioridad, respecto al uso generalizado de la aplicación a nivel mundial y local (España), siendo una de las mejores valoradas por los usuarios. 


\section{Referencias}

“Las apps preferidas en 2020” en Computer Hoy, 582, p. 19.

Blog TreceBits. Redes sociales y tecnología. $<$ https://www.trecebits.com> [Consulta: 20 de febrero de 2021].

ELOGIA. Estudio de Redes Sociales 2020. < https://iabspain.es/estudio/estudio-redessociales-2020> [Consulta: 25 de febrero de 2021].

FLORIDO, M. (2020). Curso de marketing digital. Madrid: Anaya Multimedia.

FUNDACIÓN CONTEMPORÁNEA. La cultura en España 2020. $<$ https://fundacioncontemporanea.com/wp-

content/uploads/2021/02/Observatorio_de_la_Cultura_Lo_mejor_de_la_Cultura_2020.p df $>$ [Consulta: 25 de febrero de 2021].

HOOTSUITE y WEARESOCIAL.COM. Digital 2021. Global Overview Report. $<$ https://datareportal.com/reports/digital-2021-global-overview-report> [Consulta: 25 de febrero de 2021].

HUBSPOT. The Ultimate List of Email Marketing Stats for 2020. $<$ https://blog.hubspot.com/marketing/email-marketing-stats $>$ [Consulta: 27 de febrero de 2021].

MORENO, M. (2018). La Enciclopedia del Community Manager. Barcelona: Grupo Planeta.

RAMOS, J. (2018). Marketing con WhatsApp. Guía práctica. Berlín: Juanjo C. Ramos (ebook).

STATISTA. Aplicaciones de mensajería más populares según el número de usuarios mensuales activos a nivel mundial a enero de 2021. $<$ https:/es.statista.com/estadisticas/599043/aplicaciones-de-mensajeria-mas-popularesa-1-de/\#statisticContainer> [Consulta: 27 de febrero de 2021]. 